Resenha

\title{
O "gênero" para além de uma proposição filosófica
}

\author{
“Gender" beyond philosophical proposition
}

(1) Ana Paula Hilgert de Souza*

\section{Resenha de:}

FRAISSE, Geneviève. Los excesos del género: concepto, imagén e desnudez. Madrid: Ediciones Catedra, 2016. 122 p.

Geneviève Fraisse, 68 anos, teórica francesa do pensamento feminista, tem sua produção historiográfica centrada na história da disputa entre os sexos, com enfoque epistemológico e político. A escritora possui cadeira emérita na direção do Centro Nacional de Pesquisas Científicas (CNRS), de Paris. Sua vasta produção em seu país a tornou referência nas pesquisas sobre a história das mulheres sendo reconhecida também no meio acadêmico em universidades na Espanha, Estados Unidos e México. Possui livros publicados sobretudo após os anos de 1990, como este aqui resenhado, que foi originalmente publicado em francês em 2014. Outras obras da autora são Musa de la razón: la democracia excluyente y la diferencia de los sexos (1989). Democracia e exclusão das mulheres na França (Gallimard, 1995), Mulheres e sua história (Gallimard, 1998), Los dos gobiernos: la familia y la ciudad (Gallimard, 2001), Del consentimiento (Seuil, 2007). ${ }^{1}$

Fraisse põe à disposição nesta obra, sua perspectiva ao analisar algumas controvérsias existentes em torno do debate que vem sendo produzido sobre gênero, os estereótipos de gênero e a nudez como linguagem política em manifestações de ativistas feministas. Fraisse posiciona suas análises de modo

\footnotetext{
* Doutoranda em História na Universidade Federal da Grande Dourados (UFGD, Dourados, MS, Brasil)<paulahilgert.ufgd@gmail.com>.

${ }^{1}$ Lamentavelmente, nenhuma dessas obras foi traduzida para o português. Aquelas traduzidas para a língua espanhola foram citadas nesta língua.
} 
a intervir em determinados discursos contemporâneos a respeito do conceito de gênero, os quais, a partir da segunda década do corrente século, têm sido bastante acalorados e que neste ponto servem para estabelecermos um paralelo com as discussões produzidas no Brasil, a respeito da chamada "ideologia de gênero". Os conceitos de gênero, sexo, bem como os estereótipos e a nudez são abordados sequencialmente em quatro capítulos que intencionam ilustrar os significados e usos destes conceitos traçando um percurso histórico e filosófico.

Por meio desta obra, a autora permite em sua narrativa redimensionar temáticas de gênero que estão circunscritas nas pesquisas acadêmicas e nos próprios movimentos sociais, como a dominação masculina e o relativo perigo que há na acepção da "neutralidade" existente em algumas análises sobre o gênero. No prólogo, Fraisse apresenta esse conceito como uma leitura da realidade que a nós é dada a pensar e o sugere como uma categoria adjetivada: sujeito generizado/generizada.

Promove nos (as) leitores (as) (sobretudo aqueles inseridos em pesquisas acadêmicas mexicanas, americanas, além das europeias), ${ }^{2}$ uma percepção instigante a respeito da leitura historiográfica que se inicia, refletindo a historicidade do sexo, bem como da sexuação do mundo.

Hay que levar a cabo un análises de la historicidade de dicha sexuación del mundo. Los assuntos del sexo, privados e públicos, no son simples realidades antroplógicas sometidas a variaciones, sino elementos que actúan en la historia social y política. [...] no quiere decir que haya simplemente que escribir la historia de las mujeres, de los sexos y del o de los géneros. Significará mucho más, ya que la historicidad de los sexos, como devenir y como imprevisto, prevalecerá sobre la argumentación de una evidente atemporalidad de la relación entre sexos (Fraisse, 2016, p. 58).

A leitura da obra Los excesos del género, concepto, imagén e desnudez promove interpretações capazes de fazer o (a) leitor (a) perceber como se operaram na história as transformações, as incertezas, bem como as representações produzidas sobre as mulheres, nos direcionando a refletir e indagar os papéis sociais.

Os temas suscitados pela autora validam a legitimidade daquilo que determinados grupos e movimentos sociais reivindicam, reiterando que estão inseridos em acontecimentos, nos quais as mulheres foram historicamente levadas em situações cicustanciais destacando sua representação como objet approprié et échangé, possédé et substitué, consommé et utilisé3 (objeto

\footnotetext{
${ }^{2}$ As pesquisas provenientes desses países têm mais contato com a obra da autora.

${ }_{3}$ Afirmação da autora no artigo Le devenir sujet et la permanence de l'objet (Fraisse, 2005, p. 14).
} 
apropriado e trocado, possuído e substituído, consumido e utilizado), valendose de um pensar filosófico sobre o sujeito.

Neste viés, Fraisse defende "que uma nova mirada sobre el mundo puede permitir el reconocimiento, y la representación, de que los sexos hacen la historia, y que la historia es sexuada. [...] La idea es que no podríamos pensar el mundo sin esta mirada" (p. 56). A trajetória da autora nos indica que quando generizadas, quando inseridas numa ordem dual da diferença sexual, as mulheres "ganharam" uma instituição social - o casamento - para serem inseridas na história como sujeitos sociais.

A primeira parte da obra é reservada a questionar o gênero como ferramenta de pensamento na filosofia e também a dicotomia existente entre essa categoria como um termo neutro e universal e enquanto diferenciador de "entidades", o feminino e o masculino. Com o título de Uma solución, o un problema, Fraisse analisa no primeiro capítulo, as circunstâncias e alguns significados da categoria gênero no campo dos estudos feministas. Mostra que esse debate se situa em dois campos: o gênero como uma proposição filosófica segundo a qual é possível pensar el sexo y los sexos, e enquanto um instrumento, el médio de hacer visibile, poner en practica dicha preposición, enquanto potencializa o excesso, apresentado no título e conceituado na obra. ${ }^{4}$

$\mathrm{O}$ excesso apontado no primeiro uso (o filosófico, que compreende o gênero como ferramenta de análise) é, na perspectiva da autora, epistemológico, pois ao produzir uma gama de conhecimentos dentro da teoria de gênero, aponta que o sexo, a sexuação do mundo, pode revelar e esconder comportamentos que subalternizaram a mulher na história. Assim, a obra lança uma reflexão que insere gênero, palavra por si só já excessiva, porque trata da ordem estabelecida, produz um conhecimento capaz de transbordar o marco do saber estabelecido, o que é percebido como positivo.

A filósofa destaca que o conceito de gênero antes de ser importado pelo debate filosófico, foi usado na linguagem médica, e isso teria resultado na sexuação do mundo. Aqui, Geneviève indaga se a ciência médica não estaria posta a serviço da história política. Nesse campo de pensamento, a autora alude

\footnotetext{
${ }^{4}$ Ao longo das páginas 51 a 62 a autora descreve sequencialmente os quatro excessos assinalados por ela. Resumidamente, entendo que: o 1 O Excesso: gênero não se trata de um perigo sexual, não é (unicamente) uma ameaça antropológica. O perigo está, para a autora, na organização epistemológica dos estudos feministas. O $2^{\circ}$ Excesso: É um excesso metodológico. Dificuldade de assinalar um método de análise. Exemplo da pantalla. Mostra mas também esconde. Pode-se aplicar um efeito lupa. O 3 Excesso: É a contradição entre duas vias de pensamento (ambição daqueles que correm adiante e regressão dos que não se movem do lugar) (p. 55). $\mathrm{O} 4 \mathrm{O}$ Excesso por sua vez, é positivo porque trata justamente do gênero como um novo campo de conhecimento. Correto! Mas, a autora defende que é preciso reelaborar a organização desse conhecimento. Ao longo do texto as ideias expostas aqui nesta nota serão retomadas
} 
que gênero não se trata (unicamente) de uma ameaça antropológica (que está relacionada ao fato de que os estudos de gênero se apoiam na premissa de que o gênero é construído socialmente e isso causa muita confusão em leitores não afinados com a discussão, podendo ser lido como uma ameaça à organização da sociedade), e aponta também como excesso a dificuldade de assinalar a categoria gênero como um método de análise.

O excesso aplicado ao segundo caso é apresentado pela autora como um conceito um tanto vago, borrado pelos distintos usos da palavra gênero, problematizado no segundo capítulo, Uma cuestión sin límites, no qual a autora se nega a perceber o sexo como algo dado. Nesta parte do livro, a autora analisa que o discurso sobre gênero deve supor duas discussões: a oposição natureza/biologia e cultura/sociedade e a dedução de uma realidade política de domínio (masculino). A filósofa infere que o gênero, atualmente, aparece como algo subversivo aos olhos dos conservadores e destaca que a simpatia pelos estudos de gênero é um passo adiante na defesa das liberdades pessoais.

Com cautela, ela analisa que o conceito de gênero pode produzir efeitos contrários ao desejado e pondera que este se apresenta como uma abstração que serve para pensar além da diferença dos sexos, o neutro. Essa abstração propulsiona uma contradição entre duas vias de pensamento, configurando-se como uma "encruzilhada" na qual os estudiosos tomam ou o caminho de prosseguir adiante ou regredir (nas pesquisas) por não sair do lugar. Nesse ponto, a filósofa constrói uma critica à ideia do neutro, tendo em vista que mascara ou oculta os homens e as mulheres por trás de um falso universal. Entende que "dicho neutro, el gênero puede servir de máscara que oculta a hombres e mujeres tras un universal que sabe mentir, llegando a negar, incluso, las diferencias que provocan las desigualdades" (p. 50). Além disso, ela propõe que não devemos abandonar o conceito de sexo, abolido pelas feministas.

Ao sugerir o gênero como uma presença fora de campo, Geneviève Fraisse quer demonstrar que o gênero pode ser percebido como aquilo que se deixa fora do olhar principal, indicando que sexo está além da sexualidade na medida em que ressalta que o debate sexo-gênero é tabu para a sociedade e também para o pensamento. A invisibilidade, ou o estar fora da "tela" não significa que gênero não seja nada. Ela mostra que a tela serviria para mostrar e para esconder a realidade de tal modo que o "gênero estaria muy lejos de quedar exento de caulquier ambiguidade como instrumento de análises" (p.52). Desse modo, ela sugere que é possível lançar sobre a tela um efeito lupa, que auxilie a perceber "rachaduras antropológicas". 
Ainda no segundo capítulo, Fraisse convida a repensar o vocabulário dos estudos do feminismo pós-1970, que trabalharam em duas direções: emancipação das mulheres e análise do domínio masculino. Revela-se muito provocativo o modo como Geneviève Fraisse argumenta que a ênfase dada à dominação pelas pesquisadoras daquele período configurou-se, a partir de sua análise, como prova real do domínio masculino. Nesse aspecto, a autora indica que não se trata de tornar visível o domínio, mas também é necessário desvelar sus mecanismos [da dominação] (p. 76). A ordem sexual hierárquica como motor das desigualdades de gênero deve ser percebida, para Geneviève Fraisse a partir dos discursos e práticas sobre a emancipação.

Ao problematizar no terceiro capítulo, os estereótipos e as imagens ruins que referenciam a mulher e sua posição social, a autora lembra que o movimento feminista pretende combatê-los e neste ponto ela produz uma crítica bastante relevante: a de que se atribuiu muito valor aos estereótipos ao ponto de estes combates reforçarem os modelos que os permitiram existir. A luta contra os estereótipos consiste, para a autora, em desconectar os dois sexos dos lugares e dos papéis esperados deles e permitir a dinâmica particular de cada ser sexuado, permeado em liberdades e igualdades em sentido amplo. A filósofa pontua que o estereótipo de gênero desenvolveu-se e multiplicou-se muito mais que diminuiu, nas últimas décadas. Ressalta que quanto mais se denuncia a binaridade sexuada dos estereótipos de gênero, mais ela se reproduz. Apresenta a hipótese de que denunciar esses estereótipos não só os reforça como pode outorgar-lhes consistência, permitindo-os existir.

Segundo Fraisse, muitas análises constatam que um ciclo de reivindicações, de demandas por direito, está por encerrar: a necessidade de igualdade jurídica e, mais globalmente, de qualquer transformação legislativa. Uma era de direitos igualitários, públicos e privados, cumpriramse desde a segunda metade do século 20. Igualmente, direitos de liberdades sobre o corpo foram reconhecidos tais como a contracepção, o aborto, e o reconhecimento das violências sexuais. Neste ponto, a autora vê o direito como "una potencia formal que permite, pero no garantiza de modo alguno, la transformación de las cosas" (p. 83). Ela quer mostrar que a inferioridade das mulheres ao longo da história tornou-se um lugar comum de representações sociais compartilhadas por muitos. Os estudos do feminismo que versaram sobre a dominação permitiram a mulher um status de objeto mais do que de sujeito.

Para Geneviève, o feminismo não se contentou jamais com a demanda por direitos, pois sabe-se que o movimento "é portador, em si mesmo, de uma subversão "cultural", inclusive simbólica" (p. 84). Nesta perspectiva, as lutas 
contra as imagens adquiriram sentido, renovando sua importância: destruir as más imagens seria uma maneira de registrar que o formalismo jurídico ofereceu todo o possível, mas que é necessário combater o domínio masculino de um modo distinto dos princípios políticos de igualdade e liberdade. É possível perceber, nesta leitura, que a imagem estereotipada, discutida por Fraisse, não é a causa das desigualdades, mas sim aquilo que as nutre, que as permitem desenvolver-se.

A filósofa francesa aponta que o estereótipo e os preconceitos são, por sua vez, travas na dinâmica da emancipação e considera que não se deve isolar as imagens estereotipadas do contexto em que são produzidas. Para ela, o prejuízo produzido historicamente, o domínio masculino, revelou-se na obra Los excesos del género como uma impotência social e política por não produzir uma igualdade entre os sexos desde o aparecimento da modernidade.

No último capítulo da obra, Desnudez política, Geneviève Fraisse buscou evidenciar que o corpo ocupa lugar central nos debates sobre sexo/ gênero e indica como ele promove uma ação política que fala. A nudez, portanto expressa uma argumentação. A filósofa se propõe a pensar o corpo, sobretudo aqueles presentes nos protestos de ativistas de dois movimentos sociais feministas europeus, Les Femmes e La Barbe, sendo que este último não usa da nudez propriamente, mas que ao recorrer a barbas fictícias, também sugere o corpo como uma linguagem da emancipação (p. 101). O capítulo em questão, provoca uma reflexão: $O$ corpo é portador de uma linguagem política? Respondendo positivamente, Fraisse indica que a imagem das ativistas é o resultado de uma ação real, afirmação de liberdade e de guerra, posto que, ao "explodir" no espaço público, com o corpo nu, revelando-se como uma imagem em movimento, significaria promover uma denúncia à dominação masculina.

Na perspectiva da autora, é necessário debater a questão da linguagem corporal feminina, pois o valor à imagem do corpo feminino dá-se de forma distinta em diferentes partes do mundo. Nudez versus véu. Ambos são modos de expressão, de manifestações públicas que indicam algo. Nos mandam um sinal. Na concepção da autora, a novidade na ocultação/desvelar-se é que as mulheres tomam posse de seu próprio corpo, decidindo usá-lo de forma soberana. Assim, reconhece-se a independência das mulheres como sujeitos com controle nos aspectos econômico, político e doméstico. Fraisse, neste ponto, considera o controle a independência que as ativistas fazem do corpo como características ultramodernas. Ainda que algumas mulheres usem o véu e outras se prostituam, podem manter um discurso idêntico, qual seja, de "serem proprietárias” de si mesmas, de seu pertencimento como indivíduo. 
Os meios de comunicação e a circulação digital convertem, para a autora, a imagem em um signo político rápido. Ela propõe que se estude a imagem do corpo desnudo como linguagem da emancipação. Com ou sem estereótipos, o corpo e sua imagem podem ser portadores de uma linguagem política. Fraisse pondera que nestes ativismos são corpos em movimento que atuam, com um texto escrito na pele. Esses corpos são múltiplos, chamam a atenção, orientando o olhar do espectador. Esses movimentos coincidem em uma mesma ofensiva: tratam de fazer compreender até que ponto o domínio masculino é uma presença, implícita em qualquer parte e, ao mesmo tempo, poderosa. A autora acrescenta que ver um corpo nu, na militância, não deve unicamente denunciar um estereótipo, é preciso, definitivamente, vê-lo como um gesto político. Apoiada na ideia de uma teoria de gênero questionadora de certezas travadas pelos estudos feministas pós-maio de 1968, Geneviève Fraisse demonstra que o corpo do ativismo deixa de existir como finalidade sexual na relação com o outro e passa a ser um suporte autônomo de militância que pode inclusive enunciar posições políticas.

Isto posto, a autora finaliza sua abordagem concordando que o feminismo é em si mesmo excessivo por duas razões: por falar das sexualidades e combater as desigualdades e por isso o feminismo não pode ser negado. A autora, neste trecho, traz o filósofo Friedrich Nietzsche à discussão citando a provocação do autor ao escrever "suponhamos que a verdade seja mulher", sublinhando que para este filósofo essa ideia "se trata de cuestionar mas ampliamente la verdade en si misma y su cortejo de certidumbres" (p. 109). A ideia de posse da verdade, nos leva a refletir os discursos historicamente construídos pelo patriarcado sobre a (posse) da mulher, enquanto ser sexuado, numa história que é, também, sexuada. Corpos nus, portanto, desvelam a realidade do patriarcado, conceito que é caro aos estudos de gênero. A nudez representa, para a autora, um vínculo entre a verdade associada ao corpo feminino e a verdade social e política oculta. Ela afirma que a verdade sobre as mulheres também é percebida como um excesso, pois, a análise de sua historicidade transborda de conhecimento e produziu (e continua a produzir) significativas mudanças.

Ensaio uma sutil consideração crítica sobre a obra naquilo que se refere à ausência de definição de conceitos que, para um leitor não bem ambientado com a temática circunscrita nos estudos feministas, soa como um amontoado de componentes teóricos. Também é possível perceber que Fraisse não fez questão de promover um debate entre os diferentes atores que ela enuncia no livro, o que teria sido oportuno. A leitura é válida por toda a competência da autora em propor uma discussão em que o gênero questiona a desigualdade dos 
sexos numa sociedade democrática ocidental, promovendo uma desconstrução dessa categoria de pensamento e abrindo caminhos para pesquisas, sobretudo que se debrucem em pensar o ativismo contemporâneo.

\section{Referências}

FRAISSE, Geneviève. Le devenir sujet et la permanence de l'objet. Nouvelles Questions Féministes, v. 24, n. 1, p. 14-25, 2005 <10.3917/nqf.241.0014>.

FRAISSE, Geneviève. Los excesos del género: concepto, imagén e desnudez. Madrid: Ediciones Catedra, 2016. 122 p.

Recebido em: 31 ago. 2017

Aprovado em: $10 \mathrm{dez} .2017$

Autora correspondente:

Ana Paula Hilgert de Souza

Rua Docelina Matos Freitas, 3350 - Bairro Izidro Pedroso

79840-410 Dourados, MS, Brasil 